\title{
Virtual Communities as a Mechanism for Sustainable Coordination within the South African Public Sector
}

\author{
Godwin Thomas and Reinhardt A. Botha \\ School of ICT \& Institute for ICT Advancement, Nelson Mandela Metropolitan University, \\ Port Elizabeth, 6031 South Africa \\ \{Godwin. Thomas, ReinhardtA.Botha\} @nmmu.ac.za
}

\begin{abstract}
Due to limited resources, organizations are constantly facing challenges. To take advantage of new opportunities and mitigate possible risks they look for new ways to collaborate with each other, sharing knowledge and competencies. Hence, coordination among partners is critical to achieve success. The segmented South African public sector is no different. Driven by the desire to ensure proper service delivery in the sector, various government bodies and service providers play different roles towards common goals.

As such, continuous coordination is required between the role players. This paper investigates Virtual Communities as a possible coordination artifact for supporting sustainable coordination within the South African public sector. The paper commences with a brief introduction. Thereafter, the paper carefully defines the notion of sustainable coordination. It continues then to show that Virtual Communities indeed support the requirements for sustainable coordination. Having argued this at a theoretical level, the paper moves to show how this may be applicable to the South African situation. The paper concludes by emphasizing on the value of virtual communities as separate entities to attain sustainable coordination service provision in the South African public sector.
\end{abstract}

Keywords: Sustainable coordination; Coordination mechanisms; Virtual Communities; South African public sector.

\section{Introduction}

Various types of Virtual Communities exist. These can be defined in terms of the subjects and tasks they deal with. However, they share similar characteristics. Virtual Communities can form, disband, and re-form to meet spontaneous and emerging situations. In addition, they transcend geographic location and time constraints enabling anywhere, anytime access.

Organizations are constantly faced with a dynamic and unstable environment that requires flexible and fast responses to changing and emerging business needs [1]. These requirements for agility and geographic independence are met by the properties of Virtual Communities. In addition to knowledge exchange between members, Virtual Communities may aid in coordinating work [2]. Well coordinated work processes are critical for organizational performance as they improve efficiency and produce high quality outcomes [3]. 
Coordination among stakeholders is critical to ensure sustainable development and service delivery. The South African public service is no different than other organizations in that proper coordination between the various organizations (governmental or non-governmental) charged with delivering public policy/services will prevent both redundancy and gaps in service delivery.

However, this is easier said than done. South Africa has a complex governmental structure that involves a variety of provinces, local governments and municipalities with different authority and responsibility. The three spheres of government are distinct. However, they are also interdependent as they work together towards a common governmental goal. Therefore, all the spheres of government are required to observe the principles of cooperative government set out in chapter three of the Constitution. In summary, those principles call for a clear division of roles and responsibilities, a collective approach to policy, coordination of activities to avoid duplication and waste, effective use of resources, and constructive settlement of disputes. Hence, the need for a proper and sustainable coordination service provision.

Coordination according to Malone and Crowston [4] and Gittel [3] mostly depends on underlying processes of decision-making, communication, and sharing of objects. For instance most of the coordination mechanisms require that some decision be made and accepted by a group (for example, what goal will be selected or which actors will perform which activities). In turn, group decisions require members of the group to communicate in some form about the goals to be achieved, the alternatives being considered, the evaluations of these alternatives, and the choices that are made. This communication requires that some form of "messages" be transported from senders to receivers in a language that is understandable to both. Hence, communication can be seen as a coordination device for mutual understanding.

Virtual Communities promise new possibilities for people to create, communicate and share knowledge among each other, thus forming a network. In essence, it promises support for knowledge sharing in situations requiring mutual adjustment by individuals, groups or organizations. It can capture and diffuse through the network information relevant to sustainability outcomes.

The paper sets out to identify the prospects that Virtual Communities can offer for sustainable coordination. Specifically the paper argues for its appropriateness in the South African public service that requires such coordination form to enhance and ensure proper and continuous service delivery.

In order to argue the case, it is necessary to understand the goal, being sustainable coordination, better. The next section therefore looks to characterize the concept of sustainable coordination.

\section{Characterizing Sustainable Coordination}

In order to unpack the challenges of coordination this section firstly investigates what sustainable coordination entails. Thereafter, it delves into coordination mechanisms and their associated complexities. This section therefore sets off to identify from the literature on sustainability the properties that will characterize sustainable coordination. The characteristics identified will help in mapping and analyzing the advantages virtual communities can provide (section 3). 


\subsection{Sustainable Coordination}

Underlying sustainability is the principle that we must meet the needs of the present without compromising the ability of future generations to meet their needs. Reflecting on the notion of sustainability, Fuch [5] and Rogers, Jalal and Boyd [6], based on a report by Brundtland "Our common future" [7], described sustainable development as a dynamic process of change consistent with future as well as present needs. In essence, sustainability is characterized by a continuous change process ensuring that current and future needs are met.

Attaining levels of sustainability requires the accumulation of core competences provided by individuals or organizations necessary to achieve a common purpose. Resource Dependence Theory stipulates that a single organization usually does not have all the necessary resources at its disposal [8]. Interdependency between organizations can lead to a network of organizations that collaborate, reorganizing themselves to adapt to situations quickly. According to Griffiths [9], networks are relevant to sustainability because they leverage the economies of scale and scope - they grow whilst keeping the constituent units small, flexible, responsive and innovative.

Having a common purpose is important for identifying/employing the right competencies to achieve desired outcomes. In addition, it serves as a reference point for monitoring progress and resource usage. Also characterizing sustainability is ensuring autonomy in decision making while linking relevant individualized work to meet a common purpose [8]. Hence, greater organizational commitment and employee satisfaction can be generated.

However, members forming alliances or partnerships must be willing to communicate to coordinate activities to achieve outcomes. Since a partnership means depending on each other to make decisions that will benefit all participating members a high degree of trust is required [10]. This usually entails sharing critical information between partners to achieve desired outcomes.

Furthermore, sustainability requires that limited resources are well utilized, hence the need to ensure that units of work are performed in line with a common goal. According to Jayatilaka [11] a meaningful and sustained development requires the concentrated efforts of a number of organizations managed effectively by skilled personnel. Hence, in line with Fuch, [5] projecting the need for governance. Any process in an organization needs an owner [12]; the coordination process should not be different.

While having autonomy allows freedom to act in accordance to specialized expertise, a governance framework ensuring alignment of work done to actual goal is critical. Hence, a balance between administrative control and autonomic decision making needs to be established to ensure success of an overall work process.

Drawing on the preceding discussion, Table 1 provides a summary of the properties described as characterizing sustainable coordination. We refer to the term "dynamic" in the table to represent adaptability, flexibility, agility, innovation and continuity properties mentioned in the discussion.

In order to understand the complexities associated with coordination, the next section discusses the coordination mechanisms that can be used to manage interdependencies between activities/actors. 
Table 1. Properties of sustainable coordination

\begin{tabular}{|l|l|}
\hline \multicolumn{1}{|c|}{ Properties } & Authors \\
\hline Dynamic & $\begin{array}{l}\text { Fuch [5]; Pamkowska [8]; Rogers, et al. [6]; Griffith } \\
\text { [9]; Gettel [3] }\end{array}$ \\
\hline Control/steering & Fuch [5]; Jayatilaka [11] \\
\hline Autonomy (decision making) & Griffith [9]; Ke \& Wei [10] \\
\hline Members/Partners & Griffith [9]; Pamkowska [8] \\
\hline Trust & Pamkowska [8]; Gettel [3] \\
\hline Communication & Griffith [9]; Malone and Crowston [4]; \\
\hline Common Purpose & Brunland [7] \\
\hline & Gettel [3]; Fuch [5]; Brunland, [7] \\
\hline
\end{tabular}

\subsection{Coordination Mechanisms}

Working together implies managing interdependencies among participants toward some common end [4]. Different types of interdependences and mechanisms to manage the dependencies have been identified in literature [13, 14]. Figure 1 shows coordination mechanisms to comprise two aspects: structure and process. The coordination structure provides the necessary connection to execute the process. The coordination process in a way builds the structure by facilitating communication and configuring decision making patterns. In addition, it complements modular-based structures by, for example optimally prioritizing or rearranging modules. Hence, the relationship between the mechanisms is reciprocal as they usually co-exist in an organizational setting.

Decision making, communication pattern [15] and modularization [16] constitute the three elements of coordination mechanism's structure. Modularization separates and groups system components in a variety of ways allowing much greater flexibility in end configurations [17]. Resources and capabilities need to be coordinated in adaptive ways to lead to a desired outcome, hence fostering a sustainable action of coordination. For example, a project can be divided to small manageable teams willing to collaborate to achieve a common outcome. There are a variety of coordination process mechanisms; however, they are classified in three major groups: mechanistic coordination, organic coordination and cognitive coordination. Yet, dependencies are very domain-specific, and the mechanisms to manage them must therefore be considered in a specific context as well.

In essence, there is no single blueprint or model for achieving coordination that will be adequate for all problem contexts. More likely, the coordination mechanisms or combination thereof will have to fit the type of the problem, work within the constraints and opportunities offered by the existing organizational landscape/capacity, take local political and social, economic and cultural context into consideration and adapt and innovate within space.

As shown in figure 1, new dependencies emerge through modularization, and a "shopping list" of coordination mechanisms can be selected from the catalog of controls (structure and process) to fit work context. At this level interdependent tasks are expanded, and then corresponding coordination mechanisms are inserted. 


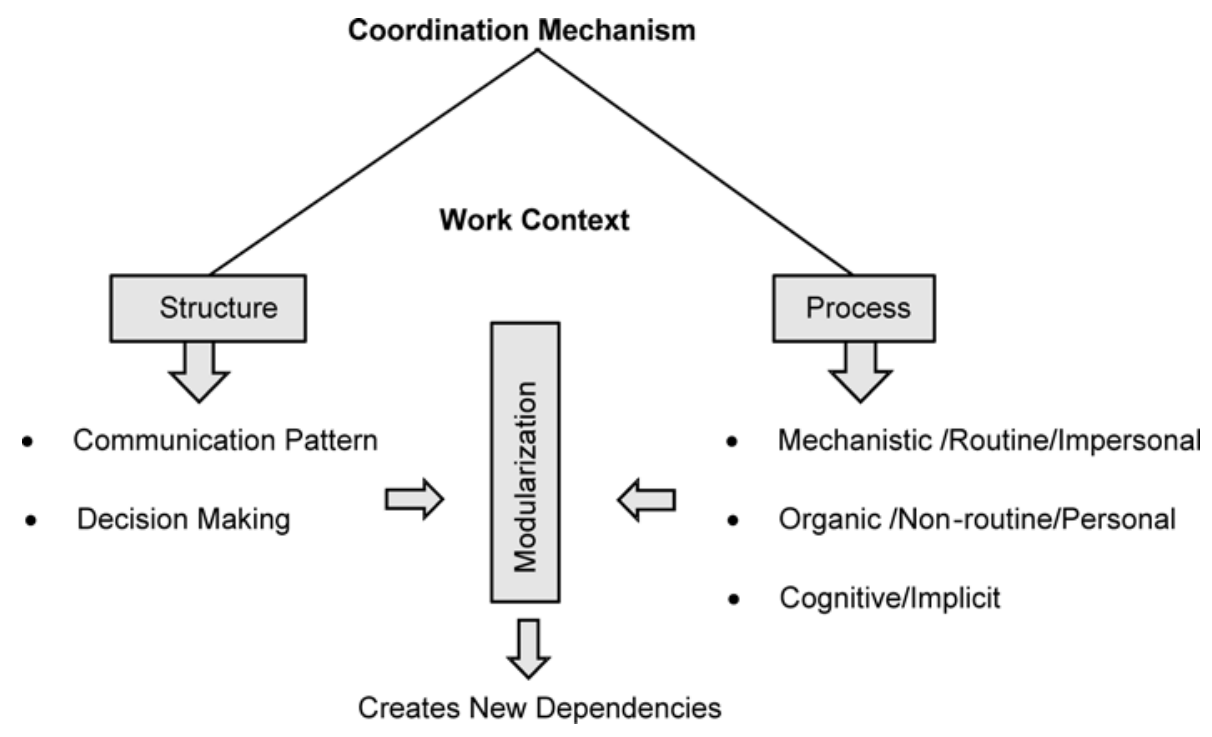

Fig. 1. Catalogue of coordination mechanisms

In order to help us attain a position of sustainable coordination the next section investigates the possible promise that the properties of virtual communities may provide.

\section{Virtual Communities}

Sustainable coordination does not happen by itself, so was the argument of this paper thus far. The previous section unpacked "sustainable coordination" and characterized it through enumerating specific requirements. This section sets out to argue that the properties exhibited by Virtual Communities promise to meet those requirements.

Virtual Communities can be described as self-organizing socio-technical systems as they exhibit both technological and social aspects [18]. They are strategic in that individuals through cooperative behaviour can be organized and focused towards actions to accomplish goals. In essence, they exhibit dynamic properties such as flexibility, adaptability, scalability and robustness. Fuch [18] describes Virtual Communities as dynamic systems based on ICT enabling communication that are regularized and structured by general rules of interaction, shared interest and general topics of interaction. Through continuous ICT-mediated communication feelings of togetherness and belonging, shared identity and common values can emerge. As such, Virtual Communities are dialectical systems in which the technological networks and social networks are interconnected and complement each other in a self-referential loop; they are self-organizing. As such, when establishing a Virtual Community, both the technological and social aspects (people and relationships) must be examined as they shape each other. 
For example, while a virtual environment can provide interaction capability (e.g. email) the sophistication level of the interaction need (e.g. real time interaction via video conferencing) may arise with time, which can be supported by technology.

\subsection{Virtual Communities for Sustainable Coordination}

Virtual communities promise sustainability as they exhibit dynamic properties. They recognize that organizations will come together (form virtual teams), disband, and reform to solve or address important issues. Hence, they can form adaptive structures to suite any given context as need arises. For example, the Open Source Network community depends on volunteers across the globe for software creation and development. Virtual teams can transcend time and space boundaries and reduce costs by effectively using ICT [19]. In addition, they gather information, diffuse knowledge that provides the potential for innovation and enable rapid and effective response (e.g. Dell computers' reliance on business partners to fulfill major parts of their supply chains).

Furthermore, sustainable coordination as mentioned requires a "common purpose". By definition the formation of Virtual Communities depends on the members having a common purpose. For example, International Open Source Network (IOSN) is focused on promoting the strategic use of free/open source software solutions for sustainable human development.

The question "how do these members know about each other" begs. The motivation to participate in a community can be intrinsic or extrinsic [20]. These motivators are the drivers capable of evoking specific outcome behaviour. Common interests can lead to relationship building in both face-to-face and virtual communities. As such, having a common purpose provides a reason to participate and interact comfortably in a virtual community. Virtual communities can be formed around an infinite number of shared interests. Participants can be drawn together when they share projects (research or work) or through referrals or contracts for a common purpose. However, communication is needed to coordinate actions.

Communication is at the centre of a community to achieve a common purpose [21]. As noted in section 2.2, communication is important to attain sustainable coordination. Virtual communities provide interactive meeting places where people can add value to work-related practices thus, communication is attained. Communication is defined by the interactions among participants supported through ICT. Virtual communities enable concurrent conversation streams and can allow other electronic information to be integrated into an interaction.

Another essential for sustainable coordination is trust. Communication is an important trust building mechanism. Virtual Communities provide an interactive environment that facilitates trust building. Increased trust and commitment among partners can facilitate the processes of knowledge sharing, participative decision making and conflict resolution, which will further enhance trust and commitment of the participants and ultimately yields better joint performance [22]. According to De Moor and Weigand [21] trustworthiness grows out of iterative processes of interaction, observation, analysis and judgement.

Virtual communities consist of a network of competencies pulled together to achieve an outcome, hence, participants remain autonomous and independent [2]. 
Virtual communities promise autonomy as they allow people to work together independently and communicate via the internet. Members maintain the responsibility for decision making and control of information concerning their competencies in a virtual community.

Based on the characteristics exhibited by Virtual communities we argue that they can support sustainable coordination. However, they must be governed properly. Virtual communities as socio-technical entities need control and steering to maintain the common interest of the community [23]. Although virtual communities support decentralized and autonomic decision making, there is a need to monitor structures, control communication and information flow among members in accordance to the communities operation principles. To define rules and coordinate actions of a community different governance models exist. This is discussed in more detail in the next section.

\subsection{Virtual Communities for Facilitating Coordination Processes}

Virtual communities can facilitate the coordination of work processes. According to the theory of relational coordination, coordination that occurs through frequent, high quality communication supported by relationships of shared goals, shared knowledge and mutual respect enables organizations to better achieve their desired outcomes. As shown by Fuch [18], the self-organizing nature of Virtual Communities promises to support relationship building. With advancement in technology, there exist applications that can supplement the face to face interaction (e.g. Skype) to further strengthen relationships.

The underlying ICT infrastructure which hosts the community supports frequent and quality interactions for mutual adjustment especially in situation of uncertainty.

Also, structure-based mechanisms can be enabled as communication and decision making pattern can be reconfigured immediately to suite context (e.g multi-user virtual games). Therefore, Virtual Communities facilitate information exchange, thus communication takes place and quality decisions can be made. With support from a coordination process repository, coordination process mechanisms can be dynamically assigned to any given business process or workflow.

Virtual teams can be assigned to coordinate activities based on a business process or workflow that possibly spans across geographical boundaries. Coordination roles or referrals in Virtual Communities can serve as structural components to positively influence trust formation in the community [23]. According to Davidow and Malone [24] coordination and control of information are critical success factors for virtual communities.

However, since the traditional mechanisms of control, management, and steering are hardly applicable in Virtual Communities, different modes of governance in the virtual environment have emerged. The appropriateness or choice of governance structure or a combination thereof will depend on the context of a community's existence. According to Ahuja and Carley [25], although virtual communities may be non-hierarchical and decentralized from an authority standpoint they may still be hierarchical and somewhat centralized from a communication standpoint.

In a continuum of two extreme modes of centralized and decentralized governance structures as shown in figure 2 four basic modes of governance can be identified [26]. 


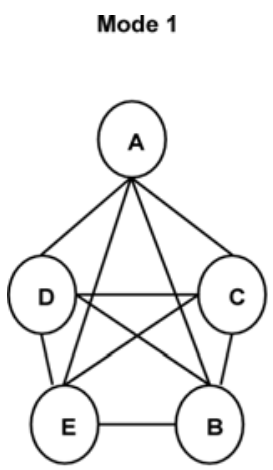

Coordinated by all partner Agencies
Mode 2

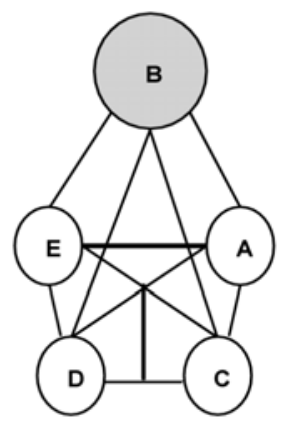

Coordinated by a broker

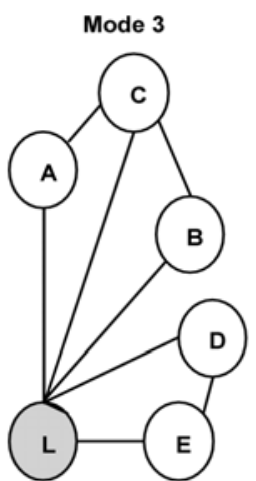

Coordinated by a partner Agency
Mode 4

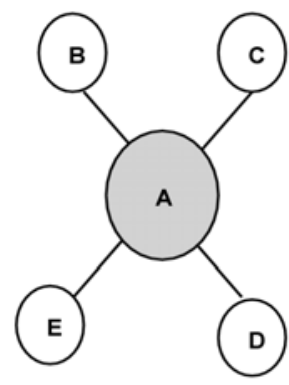

Coordinated by a central Agency

Fig. 2. The modes of governance. Adapted from Lattemann et al. [26].

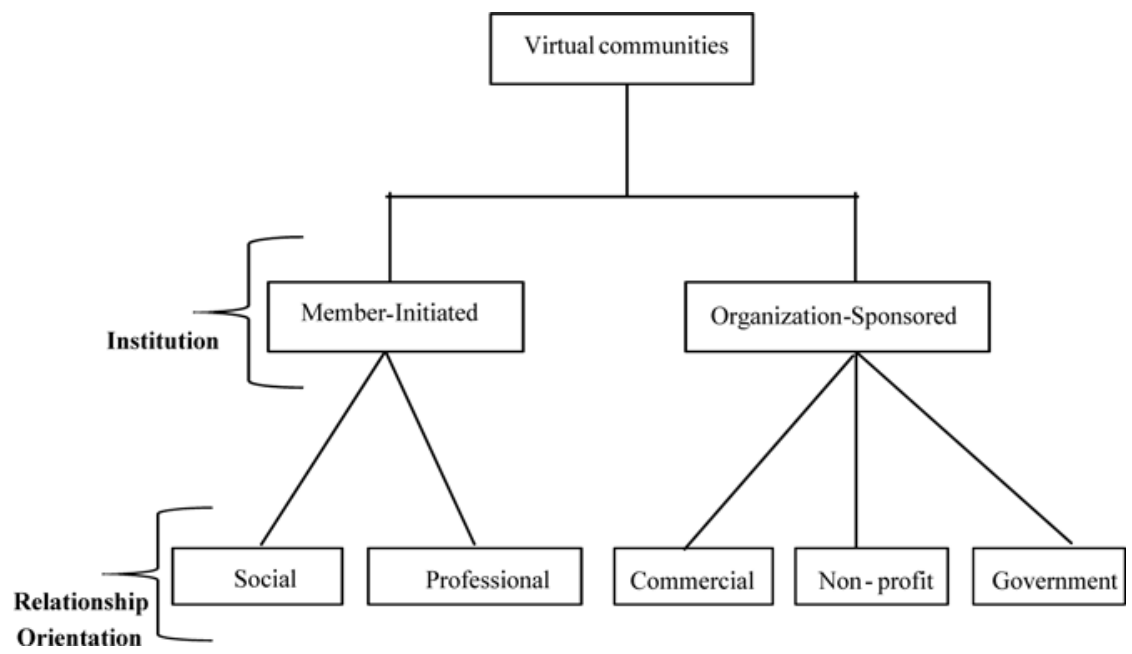

Fig. 3. A typology of virtual communities. Adapted from Porter [29].

Although Virtual communities promote autonomous decision making and encourages independent actions through modularization excessive decentralization has a strong potential to create inefficiencies, such as duplication of effort and resource wastage. To help avoid this, the management trend has shifted towards a governance structure that enables the best attributes of centralization and decentralization to be applied based on the needs of context [27]. Hence, it should not be assumed that nonhierarchical/decentralized communication structures are necessarily more effective than hierarchical/centralized structures. Rather, communication structure should be based on context characteristics. 
Furthermore, the choice of a virtual community type can influence the governance structure. Figure 3 depicts a typology of virtual communities utilizing two main categories: Member-initiated and Organization-sponsored.

In order to enable optimal organization and management of functions and contents of virtual communities, the community type must be identified and defined [28, 29]. Also, a hybrid model can be adopted. However, to select a suitable model that will cater for the need of the community it is critical to characterize the domain or need context. In effort to identify a suitable model, the next section looks at the South African public sector to define the context of existence.

\section{The South African Situation Analysis}

The South African spheres of government are distinct, but interdependent as they collectively work toward common governmental goals. However, the size of the public sector, the number of role players, not to mention shortage of skilled personnel, affects the coordination of developmental activities. Hence, greater organization and coordination efforts are required. Each entity in the public sector contributes in its unique way to the success of the government. As such, each entity has specific needs. However, these entities also have several commonalities. Thus, well-coordinated programmes need to recognize the uniqueness of each entity, while exploring economies of scale for the commonalities. In order to understand the coordination challenges and requirements this section looks to provide an analysis of the South public sector situation with specifics in terms of the capacity building initiatives. It begins by looking at the South African public sector as-is in the next section.

\subsection{The Case Status Quo}

In effort to meet the challenge of cooperative government in the South African public sector, intergovernmental forums at national and provincial level dealing with issues of alignment, integration and coherence were developed. For instance, the Integrated Developing Planning (IDP), an intergovernmental planning instrument for the whole of government calls for dialogue between spheres. Thus, national priorities are influenced and shaped by the articulation by communities of their needs through the IDP process [30]. For instance, the need for training is guided by the integrated development plan (IDP). Hence, the need for cooperation as stipulated in the constitution across spheres.

As mentioned in section 2.1, no one single actor has all the resources (knowledge/information and competence) required to solve all problems. Thus, there is wide acceptance that a decentralized set of formal and informal agreements among diverse groups and organizations in the form of networks/partnerships hold the most promising institutional prospects to achieve sustainable development [31]. This form of interdependence is prominent in the South African public service as evident in the creation of agencies to carry out specific governmental tasks. For example there are numerous role players (internal/ external) involved in a variety of capacity building efforts in terms of training in the public service [30]. The development of interdependent relationships based on trust, loyalty and reciprocity enables collaborative activity to be developed and maintained. 
However, as mentioned by Peter [32] one of the major problems facing contemporary governments is a lack of coordination and coherence across government departments or programs. This results in increased costs and reduced efficiency in the delivery of services to citizens. For instance, several training interventions in the South African public service are being made in all three spheres of government: national, provincial and local by numerous role players. However, these intervention programmes frequently illustrated misalignment with competency requirements and inappropriate content, duplication and fragmentation of efforts. In addition, there are conflicting schedules and an over-extension of staff who require the intervention. To help overcome these problems we discuss in the next section how the separation of coordination processes from work processes with Virtual Communities as the mediating artifact, can assist in meeting the coordination needs of the South African public sector.

\subsection{The Separation of Coordination Processes from Work Processes}

Considering the size and dynamic nature of the South African public service, the number of role players and communication pathways, we propose the separation of the coordination processes from the actual work processes to focus on the management of dependencies. This approach releases individuals who form nodes in the workflow from the task and worries of coordination to focus on core capabilities to provide the specialized services required in the workflow or business process. For instance, the task of consolidating and aligning training needs, scheduling, notifying and synchronizing appropriate stakeholders and monitoring should be handled as a primary task, not be imposed on employees as an extra background task.

Looking at the complexities involved in the coordination of the numerous programs/stakeholders in the South African public sector there is a need for a dedicated body to handle coordination activities hence, improve efficiency and performance. The institution should not necessarily be physical but virtual. Since work processes can span across organizational boundaries and may require high levels of flexibility we propose using virtual communities as the coordination artifact.

Virtual Communities, as mentioned in section 3.1, can serve as mechanism for sustainable coordination because the organizational model is fluid and flexible. They can provide access to skills/competencies and connect geographically dispersed members and resources.

Our proposed Virtual Community is aimed at providing a support service of coordinating work processes among stakeholders responsible for service delivery in the South African public service. The community is intended to coordinate a group of stakeholders with varying competencies, both internal (government bodies) and external partners (required competencies) pulled together to deliver value.

The Virtual Community will serve as an intermediate between partners without any self-interest. Its only objective is to improve the effectiveness of that particular community by quickly identifying the opportunities. For instance, from a holistic view of training activities, duplication and conflicts can be detected and resolved. Furthermore, groupings of training activities can help achieve economies of scale and scope.

Virtual Communities as self-organizing can maintain relationship with stakeholders, thus allowing the quick assignment of tasks to physical organizations based 
on the available information of stakeholder capabilities. All entities with potential to complete any component process can be identified. Therefore, the combination of processes to be performed, geographic location and potential prior experiences with different providers can be matched based on a given workflow. For instance, performance of training providers can be tracked and recorded for future decision making on subsequent training required.

Virtual Communities can provide tracking and aid assessment capability, hence increase service provision satisfaction. However, there must be appropriate feedback from cooperating agencies to the Coordinating Virtual community indicating process status to effectively manage an entire process. Thus, notification to relevant members can be established and if necessary allocate work to another when problems occur.

However, the type of services to be provided or the needs will determine the nature or type of community to be formed (e.g. for mentorship programmes or share experiences on training provided). As such questions about community types and appropriateness arise. The next section looks to answer the question on the type of community we deem appropriate for our case context.

\subsection{The Virtual Community Formation}

In forming a Virtual Community to attain sustainable coordination, considering the different types of existing communities as illustrated in section 3.2, we lean towards organization-sponsored communities. As primary stakeholders in the public service, the government should drive the process. As mandated by the constitution they have the primary objective of delivering service to the public through well coordinated collaborative means. The motivation here should be intrinsic since a higher commitment should be expected.

While commercial entities' participation in a community will probably be short lived (level of commitment), most often based on the duration of a project, government agencies as core members will be charged with the continual service provision. We recognise that in this case, the concern is not about sustaining the organization in terms of longevity, but rather recognising that in the search for sustainability there will be need for limited term or temporary projects. Hence, organizations will come together to solve the issues and disband once they have been addressed. Government agencies are required to look for opportunities to collaborate leveraging the economy of scale and scope. As such, government based agencies are in a position to serve as the member organization that can define the rules of the community and coordinate the actions of members respectively. For example, the Department of Provincial and Local Government (DPLG) a key role player with the responsibility of strengthening capacity to coordinate capacity building and service delivery can take the lead. However, the question on how to control or govern the behavior of members arises. The next section attempts to address the question.

\subsection{The Virtual Community Governance}

Overall, the complexity and nature of the public service can give rise to, conceptually, one large community consisting of all participants and composed of many smaller communities or sub-communities for different kinds of needs or context. Due to trust 
and control issues that might arise the role of "community coordinator" can be fulfilled by a group of individuals selected from different participating governmental agencies anchored by the process owner to form a central broker. For instance, when a certain business process is in action, a team to oversee the process can be generated dynamically. For example, dynamically generating teams based on classification of training types (e.g. training area, mentorship) or duration (short-term or long-term). As such representatives of contracted external bodies can be members until the project is completed. By establishing groups within the community that represent all the participants' interest, cooperative behaviours are likely to be induced and prevail. A neutral broker institution (possesses knowledge of the business process) can support the partners with coordination, without establishing any hierarchy.

A hybrid governance model that maintains both centralized and decentralized modes of coordination is desirable. While peer-to-peer communications might be very efficient in a situation where a project affects few individuals only; in a large community inefficiencies and duplications can be introduced. Hence, it is essential to form strategic partnerships, organize network activities and identify new collaboration opportunities to improve overall effectiveness. By increasing community coordination efficiency in an overall work process can be improved.

\section{Conclusion}

It has been established that there is a need for a mechanism that can aid in the achievement of a sustainable coordination of developmental activities within the South African public service. We propose that one strategic approach to attaining such a goal is through the separation of coordination processes from work processes supported by Virtual Community as the mediating artifact. Virtual Communities can unify the intent of organization(s) and focus members towards processes designed to accomplish a desired outcome. We maintain that because Virtual Communities provide an interactive environment that transcends location and time, provide flexibility and innovation, they can support suitable coordination. Rapid decision-making pertaining to tasks in a geographically distributed environment is possible. Separating coordination from actual physical work processes helps in avoiding duplication of effort and allows for reuse of knowledge gained by the coordinating team. The community can evolve through learning, and relationships strengthened through sharing, hence it is self-organizing.

Inspired by ICT, a virtual community provides a lot of advantages. However, understanding the technology is not enough, social aspects (people and relationships) need to be examined to achieve success. We suggest the use of a community coordinator (teams) to enhance relationships and trust in the community. Furthermore, established teams should be anchored by a coordination process owner, due to their knowledge and understanding of the domain. The selection of a governance structure depends on the context of the activity performed and can evolve as the context change. Thus Virtual Communities are capable of solving problems through varied adaptive partnership or structure reorganization. Hence, we believe Virtual Communities can serve as ideal mechanisms for coordinating work processes. 
However, Communities typically make unstructured decisions under condition of uncertainty. Therefore an integrated knowledge management system that spans geographical boundaries is desirable. Such an infrastructure will enable and facilitate knowledge flows among participating organizations. Needed knowledge can then get to the relevant participants on a timely basis in a suitable and affordable manner to accomplish their common goal.

\section{References}

1. Keinänen, K., Oinas-Kukkonen, H.: Virtual organizing as a strategic approach to stay competitive-: a conceptual analysis and case study. IGI Publishing Hershey, Pensylvania (2001)

2. Sagers, G.W., Michael, D.H., Wasko, M.M.: Coordinating Efforts in Virtual Communities: Examining Network Governance in Open Source. In: Proceedings of the Tenth Americas Conference on Information Systems, New York, pp. 2697-2698 (2004)

3. Gittel, J.H.: Coordinating mechanisms in care provider groups; Relational coordination as a mediator and input uncertainty as a moderator of performance effects. Managment Science 48, 1408-1426 (2002)

4. Malone, T.W., Crowston, K.: The interdisciplinary study of coordination. ACM Computing Surveys, 87-119 (1994)

5. Fuch, C.: Towards a Global Sustainable Information Society (GSIS)? tripleC - Cognition. Communication, Co-operation 4(1) (2006)

6. Rogers, P.P., Jalal, K.F., Boyd, J.A.: An introduction to sustainable development. Earthscan Publications Ltd., London (2008)

7. Brundtland, G.H.: Our Common Future, The World Commission on Environment and Development. Oxford University Press, Oxford (1987)

8. Pamkowska, M.: Autopoiesis in Virtual Organizations. Advanced Information Technologies for Management - AITM 2007. Revista Informatica Economică 1, 33-39 (2008)

9. Griffiths, A.: Corporate architectures for sustainability. International Journal of Operations \& Production Management 21, 1573-1585 (2001)

10. Ke, W., Wei, K.K.: Factors affecting trading partners' knowledge sharing: Using the lens of transaction cost economics and socio-political theoriesstar, open. Electronic Commerce Research and Applications 6, 297-308 (2007)

11. Jayatilaka, W.: Capacity Building for Sustainable Development. J. Natn. Sci. Foundation Sri Lanka 36, 81-97 (2003)

12. West, J., Cianfrani, C.A.: Unlocking the power of your QMS: keys to performance improvement. American Society for Quality, Milwaukee (2004)

13. Mintzberg, H.: The structuring of organizations. Prentice Hall, Engelwood Cliffs (1979)

14. Malone, T.W.: What is Co-ordination Theory? Working Paper. Sloan School of Management, Massachusetts Institute of Technology (1998)

15. Malone, T.W.: Modeling Coordination in Organizations and Markets. Management Science 33, 1317-1332 (1987)

16. Shen, S.Y., Shaw, M.J.: Managing Coordination in Emergency Response Systems with Information Technologies. In: Proceedings of the Tenth Americas Conference on Information Systems. Association for Information Systems, New York (2004)

17. Schilling, M.A.: Toward a General Modular Systems Theory and Its Application to Interfirm Product Modularity. Academy of Management Review 25, 312-334 (2000) 
18. Fuchs, C.: Towards a dynamic theory of virtual communities. International Journal of Knowledge and Learning 3, 372-403 (2007)

19. Lucca, J., Sharda, R., Weiser, M.: Coordinating Technologies for Virtual Organization. Mobile Computing 19, 31-51 (2002)

20. Ryan, R.M., Deci, E.L.: Self-determination theory and the facilitation of intrinsic motivation, social development and well-being. American Psychologist 55, 65-78 (2006)

21. de Moor, A., Weigand, H.: Effective Communication in Virtual Adversarial Collaborative Communities. The Journal of Community Informatics 32, 223-247 (2006)

22. Chi, L., Holsapple, C.W.: Understanding computer mediated interorganizational collaboration: a model and framework. Journal of Knowledge Management 9, 53-75 (2005)

23. Akram, A., Allan, R., Rana, O.: Virtual communities and community coordinator. In: 2005 International Conference on Semantics, Knowledge and Grid (SKG 2005), Beijing, China, November 27-29, p. 110. IEEE Computer Society, California (2005)

24. Davidow, W.H., Malone, M.S.: The Virtual Corporation - Structuring and Revitalizing the Corporation for the 21st Century. Harper Collins, New York (1992)

25. Ahuja, M., Carley, K.: Network Structure in Virtual Organizations. Organization Science 10, 741-747 (1999)

26. Lattemann, C., Kupke, S., Stieglitz, S.: The Governance of Virtual Corporations. Journal of E-Business 7, 53-64 (2007)

27. Ulrich, W.M.: IT Centralization versus Decentralization: The Trend Towards Collaborative Governance, System Transformation Portal, http: / / www. systemtransformation.com/ Org_Transformation_Articles/org_decentralization.htm (retrieved October 25, 2009)

28. Markus, U.: Characterizing the virtual community, SAP Design Guild, 5th edn. (2002), http: / /www. sapdesignguild.org/editions/edition5/ communities.asp (retrieved October 1, 2004)

29. Porter, C.: A typology of virtual communities: a multi-disciplinary foundation for future research. Journal of Computer Mediated Communication 10 (2004)

30. DPLG, \& SALGA.: National Capacity Building Framework for Local Government. Pretoria: Department of Provincial and Local Government (2008)

31. Muller, K.: Sustainable Development: The Question of Integration and Coordination. Journal of Public Administration 39, 398-410 (2004)

32. Peter, B.G.: Managing Horizontal Government: The Politics of coordination. Public Adminstration 76, 295-311 (1998) 